\title{
Gastrointestinal Tumors of the Colon and Rectum
}

\author{
Dimitra G. Theodoropoulos, M.D. ${ }^{1}$
}

\section{ABSTRACT}

Gastrointestinal stromal tumors (GISTs) of the colon and rectum are the most common mesenchymal tumors of the gastrointestinal tract. GISTs of the colon and rectum constitute $\sim 5 \%$ of all cases. Although colorectal GISTs can be small and found incidentally, the majority appear to be high risk and carry a significant likelihood of recurrent and metastatic disease. Surgery remains the mainstay of treatment for primary disease. There is now considerable interest in GISTs because they can be treated effectively with targeted molecular therapies, specifically tyrosine kinase inhibitors (TKIs), such as imatinib mesylate and sunitinib malate. GISTs are best treated by a multidisciplinary team comprised of the surgeon, medical oncologist, pathologist, and radiologist in the initial evaluation, management, and in continued follow-up. Increasing the number of resectable cases through pharmacologic debulking, optimizing the timing of surgery and organ preservation, reducing recurrence and surgical morbidity, prolonging survival, and possibly enhancing response to imatinib through surgical cytoreduction are all potential benefits of multidisciplinary management.

KEYWORDS: Colorectal/rectal GIST, prognostic factors, neoadjuvant/adjuvant imatinib

Objectives: On completion of this article, the reader should be able to summarize the diagnosis, specific characteristics, and management of gastrointestinal stromal tumors of the colon and rectum.

\section{BACKGROUND}

Gastrointestinal stromal tumors (GISTs) are the most common mesenchymal tumors of the gastrointestinal (GI) tract. The incidence of all-site GISTs in the United States is estimated at 3300 to 4350 annually. ${ }^{1}$ They occur most often in the stomach (60\%) and the small intestine (30\%). GISTs of the colon and rectum constitute $\sim 5 \%$ of all cases and occur more often in the rectum ${ }^{2}$ than the colon. ${ }^{3}$ The incidence of anorectal GISTs is estimated at $\sim 200$ to 400 cases per year. They comprise $0.1 \%$ of all colon and rectal tumors. There are few data available for colorectal GISTs to guide management, and the prog- nosis has been historically poor. Recent advances in molecular biology with the introduction of effective targeted molecular therapies for GISTs have raised awareness for all these tumors and improved the possibility of cure.

\section{PATHOGENESIS}

GISTs appear to arise from the interstitial cells of Cajal (ICCs) or their stem cell precursors. ${ }^{4}$ ICCs are located in the myenteric plexus of the gut wall and participate in the generation of the pacemaker activity of the gut; they
${ }^{1}$ Department of Surgery, North Shore University Hospital, Manhasset, New York.

Address for correspondence and reprint requests: Dimitra G. Theodoropoulos, M.D., 310 East Shore Rd., Ste. 203, Great Neck, NY 11023 (e-mail: dtheodorop@nshs.edu).

Uncommon Colorectal Neoplasms; Guest Editor, Craig A.

\section{Reickert, M.D.}

Clin Colon Rectal Surg 2011;24:161-170. Copyright (C) 2011 by Thieme Medical Publishers, Inc., 333 Seventh Avenue, New York, NY 10001, USA. Tel: +1(212) 584-4662.

DOI: http://dx.doi.org/10.1055/s-0031-1286000.

ISSN 1531-0043. 
regulate intestinal motility and autonomic nerve function. They express the cell surface markers CD117, or cKIT, a transmembrane receptor protein tyrosine kinase, and CD34, a hematopoietic progenitor cell antigen. GISTs appear to arise from gain-of-function mutations in the c-kit tyrosine kinase of the ICCs; such mutations result in the tyrosine kinase being in a continuously activated state. Kit protein normally regulates cell proliferation and differentiation, cell adhesion and apoptosis. Mutations causing continuous activation of the tyrosine kinase lead to uncontrolled cell proliferation and resistance to apoptosis.

Most KIT mutations in GISTs involve the exon 11 , the juxtamembrane domain. This region, just inside the cell membrane, apparently represents an inhibitory region regulating the KIT activation. Other KIT mutations found in GISTs occur, in decreasing order of frequency, in exons 9 (extracellular domain), 13, and 17. ${ }^{5}$ The prognostic value of KIT exon 11 mutations is controversial. ${ }^{6}$ Some studies showed that these mutations are more common in large, mitotically active tumors, or correlate with malignant disease. ${ }^{7,8}$ However, others have indicated that KIT exon 11 mutations are a ubiquitous feature of GISTs and are found in malignant as well as in clinically indolent, benign tumors. ${ }^{9,10}$ The exon $11 \mathrm{mu}-$ tations are heterogeneous, and it appears that the type of mutation may correlate with clinical outcome. ${ }^{11,12}$

Most KIT-mutant proteins are sensitive to the tyrosine kinase inhibitor imatinib mesylate. Imatinib binds specifically to the kinase domain of these receptors to cause frequently dramatic regression in CD117-positive GISTs. However, exon 9 mutants occur predominantly in intestinal GISTS and are less sensitive to imatinib. ${ }^{6}$ Secondary KIT mutations (occurring after treatment with TKIs) affect exons 13 through 17. GISTs with secondary mutations in exon 13 and 14 are sensitive to sunitinib, another tyrosine kinase inhibitor. ${ }^{6}$

GISTs with no detectable KIT-expression have been reported in the range of $17 \%$ for the colon and rectum and 9\% specifically for the rectum. ${ }^{13,14}$ Approximately $35 \%$ of KIT negative GISTs carry activating mutations in the PDGFRa gene. PDGFRa is the platelet-derived growth factor receptor $\alpha$ and is a tyrosine kinase receptor with a similar role in oncogenesis. ${ }^{15}$ The most common PDGFRa mutation is an Asp842Val substitution in exon 18 and GISTs with this mutation are resistant to imatinib. PDGFRa mutations are usually associated with gastric GISTs, epithelioid morphology, and a less malignant course of disease. ${ }^{6}$

The National Comprehensive Cancer Network (NCCN) GIST Task Force does not recommend routine use of mutational analysis in primary GISTs. ${ }^{16}$ The Task Force acknowledges that current data suggest mutational status has both prognostic significance and impact on response to TKI therapy. At the same time, the existing data are only preliminary and insufficient to mandate routine use of mutational analysis for recurrence risk stratification. However, analysis is recommended in selected primary cases and in the treatment of metastatic or advanced disease.

\section{PRESENTATION AND DIAGNOSIS}

Rectal GISTs have been reported in adults between the ages of 17 and 90, with a mean age of 59 years. There is a significant male predominance. Rectal GISTs may present in any way from small asymptomatic intramural nodules to large masses that bulge into the pelvis and cause pain, rectal bleeding, obstruction, or symptoms of prostatitis. $^{2}$

Colon GISTs have a mean age of presentation of 62 years, with a range of 28 to 82 years. They have even sex distribution, and occur more commonly in the left or transverse colon (71\%). They are typically transmural tumors with frequent intraluminal and outward bulging components. Small colon GISTs can be found incidentally, whereas larger ones present with lower GI bleeding, abdominal pain, perforation, obstruction, and an abdominal or pelvic mass. ${ }^{3}$

The imaging modalities most commonly used in the evaluation of colorectal GISTs are computed tomography (CT), magnetic resonance imaging (MRI), and endoscopic/endorectal ultrasound (EUS). Typically GIST is a solid hyperdense-enhancing mass with no surrounding lymphadenopathy on CT and MRI. Large rectal GISTs appear as circumscribed heterogeneous masses with areas of hemorrhage or necrosis (Fig. 1). ${ }^{17}$ Multiphasic CT imaging techniques are required to recognize the hypervascular hepatic metastases from GISTs, which can be otherwise missed in the routine portal venous phase imaging. ${ }^{16}$ Endoscopic ultrasound can demonstrate the origin of the tumor from the muscularis propria and the layers of the wall involved by the tumor. ${ }^{18,19}$

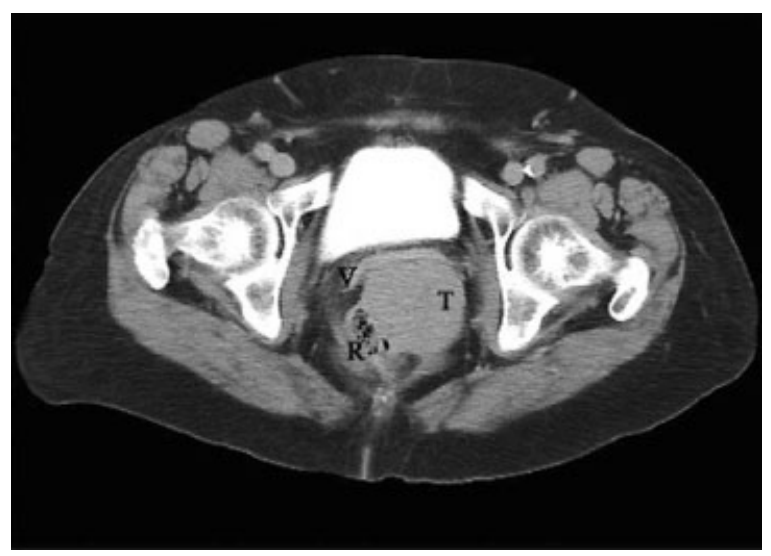

Figure 1 Computed tomography scan showing a rectal gastrointestinal stromal tumor extending from the anterior rectal wall. Notice the bulging of the vaginal wall. $\mathrm{V}$, posterior vaginal wall; $R$, rectum; $T$, tumor. Adapted from Hellan, Maker. $^{46}$ 
Pretreatment biopsy of tumors suspected to be GISTs has been controversial. ${ }^{20}$ These tumors tend to be soft and friable, and there is concern that biopsy may cause tumor rupture or bleeding and lead to tumor dissemination or seeding of the biopsy tract. Furthermore, the diagnosis of GIST in many cases can be highly suspected based on endoscopic ultrasound (EUS). Recent reports indicate that EUS-guided fine needle aspiration is a safe and accurate method for definitive diagnosis of GIST. ${ }^{21-23}$ Overall, biopsy may not be necessary if the tumor is easily resectable and preoperative therapy is not required. Conversely, biopsy may be needed if preoperative therapy is being considered for unresectable or marginally resectable tumors. ${ }^{16}$ The NCCN GIST Task Force reported preference for core needle biopsy samples over fine needle aspirations, because they may provide information regarding the mitotic rate.

\section{HISTOLOGY AND IMMUNOHISTOCHEMISTRY}

Histologically, the majority of colon and rectal GISTs are spindle cell tumors. ${ }^{2,3} \mathrm{~A}$ small percentage has epithelioid morphology. Small GISTs sometimes have extensive calcification, that may reflect their long natural history and tendency to spontaneous regression.

Histologic grading, an important component of soft tissue sarcoma staging, is not well suited to GISTs because most of these tumors have low or relatively low mitotic rates below the thresholds used for grading of soft tissue tumors. Furthermore, GISTs often manifest aggressive features with mitotic rates below the thresholds used for soft tissue tumor grading (the lowest tier of mitotic rates for soft tissue sarcomas being 10 mitoses per 10 high-power field [HPF]). In GIST staging, the grade is determined entirely by mitotic activity; lowgrade tumors have a mitotic rate equal or less than 5 per $50 \mathrm{HPF}$ and high-grade tumors have a mitotic rate higher than 5 per $50 \mathrm{HPF}^{1}$

CD117, the antigen corresponding to the KIT protein, is the most specific defining marker for GISTs. ${ }^{24}$ Approximately $95 \%$ of GISTs are positive for KIT (CD117). Miettinen et al reported on the clinicopathologic features of 133 anorectal GISTs; 100\% were positive for CD117 (this was part of the definition of GISTs), 94\% were positive for CD34, 8\% were positive for smooth muscle actin (SMA), and 1\% was positive for desmin. ${ }^{2}$ The same group reported on 37 colonic GISTs; $76 \%$ of cases were CD117 positive, 59\% CD34 positive, $23 \%$ actin positive; all were desmin negative. ${ }^{3}$

CD34 is the hematopoietic progenitor cell antigen and another marker commonly seen in GISTs. Its expression varies depending on the anatomic location and has been reported to be close to $100 \%$ in rectal GISTs, but in the range of $50 \%$ for small bowel GISTs. Smooth-muscle markers are the smooth muscle actin
(SMA), desmin, and h-caldesmon (HCD). SMA expression has opposite patterns than CD34, being more frequent in the GISTs of small bowel (50\%) and rarest in the GISTs of rectum and esophagus $(<10 \%) .{ }^{25}$ Desmin and S-100 are seen rarely. Nestin is another marker and has been reported positive in $90 \%$ to $100 \%$ of GISTs. ${ }^{26}$

Non-GIST tumors that are positive for KIT include metastatic melanoma, angiosarcoma (50\%), the Ewing sarcoma family of tumors (50\%), childhood neuroblastoma (30\%), malignant fibrous histiocytoma, extramedullary myeloid tumor, seminoma, Merkel cell carcinoma, and small cell lung carcinoma. These tumors, however, have not been shown to respond to imatinib treatment because they are not driven by pathogenic KIT mutations. ${ }^{27}$ GISTs can be confidently diagnosed if the morphology and immunophenotype are concordant; however, tumors with any unusual features should be sent to a referral institution with special expertise. ${ }^{16}$

Leiomyomas and leiomyosarcomas are the main tumors of the GI tract that are often confused with GISTs. Their well-differentiated smooth muscle cells are negative for KIT and CD34 and positive for SMA, and usually for desmin. ${ }^{28}$ Schwannomas are distinguished from GISTs by their positivity for S-100 and negativity for smooth muscle markers and KIT. Solitary fibrous tumors occur in the GI tract, mesentery, or retroperitoneum and mimic GISTs histologically. They are typically CD34 positive and negative for KIT and smooth muscle markers. Desmoid-type fibromatoses (DTFs) may be distinguished from GISTs by their expression of $\beta$-catenin. Inflammatory fibroid polyps are CD34-positive and KIT-negative benign lesions. ${ }^{25}$

\section{PROGNOSTIC FACTORS}

The two most important prognostic factors for GISTs are tumor size and mitotic index of activity, described as the number of mitoses per $50 \mathrm{HPF}$. It is now accepted that all GISTs have malignant potential. ${ }^{29}$ This concept was originally upheld in a consensus approach to risk stratification of GISTs published in 2002 (Table 1), and was further supported by three large retrospective studies by Miettinen et al. ${ }^{30-32}$ A TNM classification system for GISTs was produced in 2010 (Table 2). ${ }^{32 a}$

Studies indicate that anatomic location also affects the risk for disease recurrence and progression. ${ }^{33}$ GISTs of the small intestine are more aggressive than gastric GISTs of equal size. ${ }^{34}$ Dematteo et al evaluated 127 patients with completely resected GISTs and found that recurrence of the disease was independently predicted by mitotic rate, tumor size, and tumor location. ${ }^{35}$ The study population included 14 patients with GISTs of the colon and rectum grouped together, although only one patient had a colon primary. These patients had a high rate of recurrence, with only $20 \%$ free of recurrence after long-term follow-up. Positive microscopic margins 
Table 1 National Institutes of Health Consensus Criteria for Assigning Risk to Gastrointestinal Stromal Tumors

\begin{tabular}{lll}
\hline Risk & Size (cm) & Mitotic Count (HPF) \\
\hline Very low & $<2$ & $<5 / 50$ \\
Low & $2-5$ & $<5 / 50$ \\
Intermediate & $<5$ & $6-10 / 50$ \\
& $5-10$ & $<5 / 50$ \\
High & $>5$ & $>5 / 50$ \\
& $>10$ & Any mitotic rate \\
& Any size & $>10 / 50$ \\
\hline
\end{tabular}

HPF, high-power field.

Adapted from Fletcher et al. ${ }^{29}$

were more likely in the rectum (38\%) than the stomach or small intestine.

Table 3 shows the guidelines suggested by Miettinen et al at the Armed Forces Institute of Pathology (AFIP) for the risk stratification of primary GISTs based on size, mitotic index, and site. ${ }^{34}$ Their data were based on long-term follow-up of more than 1800 GISTs, including 111 rectal tumors. In their study, small rectal GISTs, $<2 \mathrm{~cm}$ in size, with a mitotic index of $\leq 5$ per 50 HPF were essentially benign; the risk of malignancy increased for larger tumors with the same mitotic index. Rectal tumors with a mitotic index of $>5$ per $50 \mathrm{HPF}$ had a high risk for progressive disease independent of their size.

Gold et al developed a nomogram to predict the 2-year and 5-year recurrence-free survival (RFS) after complete surgical resection of localized GISTs (Fig. 2) ${ }^{36}$ The nomogram assigns points for size, mitotic index, and site of origin. It was based on 127 patients treated at Memorial Sloan-Kettering Cancer Center (MSKCC); its performance was validated in two comprehensive GIST series-the Spanish Group for Research on Sarcomas (212 patients) and the Mayo Clinic (148 patients). The nomogram appears to be slightly better than the $\mathrm{NIH}^{29}$ and the $\mathrm{AFIP}^{1}$ criteria in predicting the probability of recurrence-free survival. It may be useful in patient care, interpretation of results, and selection of patients for postoperative imatinib therapy.

Various immunohistochemical markers have been shown to be adverse prognostic factors in rectal GISTs, such as the proliferating marker Ki67, the p53 tumor suppressor gene, and the p21 nuclear protein. ${ }^{37,38} \mathrm{Ex}-$ pression of the hepatoma-derived growth factor (HDGF) and the proliferating cell nuclear antigen

Table 2 The 2010 TNM Classification for GISTs*

\begin{tabular}{|c|c|c|c|c|c|}
\hline Tumor Size (cm) & Mitoses/50 HPF & T-Stage Gastric & T-Stage Nongastric & UICC Gastric & UICC Nongastric \\
\hline$\leq 2 \mathrm{~cm}$ & $\leq 5$ & T1 & $\mathrm{T} 1$ & IA & I \\
\hline$>2-5 \mathrm{~cm}$ & $\leq 5$ & $\mathrm{~T} 2$ & $\mathrm{~T} 2$ & IA & I \\
\hline$>5-10 \mathrm{~cm}$ & $\leq 5$ & T3 & T3 & IB & II \\
\hline$>10 \mathrm{~cm}$ & $\leq 5$ & $\mathrm{~T} 4$ & $\mathrm{~T} 4$ & II & IIIA \\
\hline$\leq 2 \mathrm{~cm}$ & $>5$ & $\mathrm{~T} 1$ & $\mathrm{~T} 1$ & II & IIIA \\
\hline$>2-5 \mathrm{~cm}$ & $>5$ & $\mathrm{~T} 2$ & $\mathrm{~T} 2$ & II & IIIB \\
\hline$>5-10 \mathrm{~cm}$ & $>5$ & T3 & T3 & IIIA & IIIB \\
\hline$>10 \mathrm{~cm}$ & $>5$ & $\mathrm{~T} 4$ & $\mathrm{~T} 4$ & IIIB & IIIB \\
\hline
\end{tabular}

* The above UICC stages are valid for NO MO tumors. All tumors with lymph node or other metastasis are considered UICC stage IV. UICC, International Union Against Cancer.

Adapted from Agaimy. ${ }^{32 a}$

Table 3 Risk Stratification of Primary GIST by Mitotic Index, Size, and Site

\begin{tabular}{|c|c|c|c|c|c|}
\hline \multicolumn{2}{|l|}{ Tumor Parameters } & \multicolumn{4}{|c|}{ Risk for Progressive Disease* $(\%)$, Based on Site of Origin } \\
\hline Mitotic Rate (HPF) & Size & Stomach & Jejunum/lleum & Duodenum & Rectum \\
\hline \multirow[t]{4}{*}{$\leq 5 / 50$} & $\leq 2 \mathrm{~cm}$ & None $(0 \%)$ & None $(0 \%)$ & None $(0 \%)$ & None $(0 \%)$ \\
\hline & $>2, \leq 5 \mathrm{~cm}$ & Very low (1.9\%) & $\operatorname{Low}(4.3 \%)$ & $\operatorname{Low}(8.3 \%)$ & $\operatorname{Low}(8.5 \%)$ \\
\hline & $>5, \leq 10 \mathrm{~cm}$ & $\operatorname{Low}(3.6 \%)$ & Moderate (24\%) & Insufficient data & Insufficient data \\
\hline & $>10 \mathrm{~cm}$ & Moderate (10\%) & High $(52 \%)$ & High (34\%) & High $(57 \%)$ \\
\hline \multirow[t]{4}{*}{$>5 / 50$} & $\leq 2 \mathrm{~cm}$ & None $^{\dagger}$ & $\mathrm{High}^{\dagger}$ & Insufficient data & High (54\%) \\
\hline & $>2, \leq 5 \mathrm{~cm}$ & Moderate (16\%) & High $(73 \%)$ & High (50\%) & High $(52 \%)$ \\
\hline & $>5, \leq 10 \mathrm{~cm}$ & High $(55 \%)$ & High $(85 \%)$ & Insufficient data & Insufficient data \\
\hline & $>10 \mathrm{~cm}$ & High $(86 \%)$ & High $(90 \%)$ & High $(86 \%)$ & High (71\%) \\
\hline
\end{tabular}

*Defined as metastasis or tumor-related death.

'Denotes small number of cases.

Data are based on long-term follow-up of 1055 gastric, 629 small intestinal, 144 duodenal, and 111 rectal GISTs

GIST, gastrointestinal stromal tumor; HPF, high-power field.

Adapted from Miettinen, Lasota. ${ }^{34}$ 


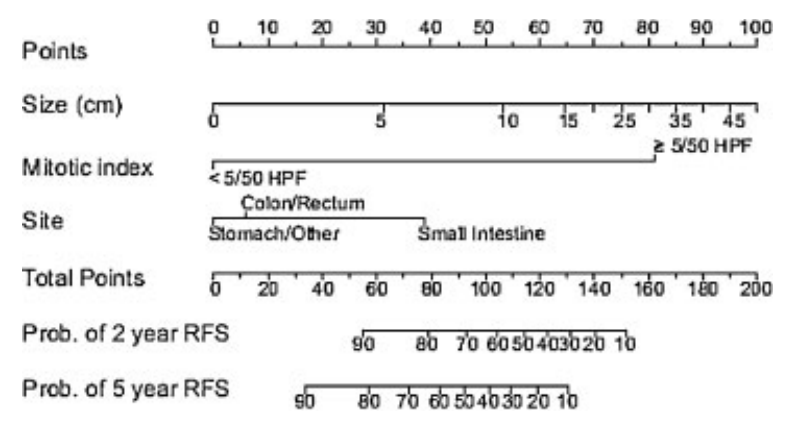

Figure 2 Nomogram for predicting probabilities of 2- and 5year recurrence-free survival. Points are assigned for size, mitotic index, and site of origin by drawing a line upward from the corresponding values to the "Points" line. The sum of these three points, plotted on the "Total Points" line, corresponds to predictions of 2- and 5-year recurrence-free survival. HPF, high-power field; RFS, recurrence-free survival. Adapted from Gold et al. ${ }^{36}$

(PCNA) have been associated with poor prognosis in colorectal GISTs. ${ }^{39,40}$ Finally, mucosal invasion has been noted as an adverse prognostic factor in numerous studies. ${ }^{41,42}$

\section{SURGERY FOR PRIMARY DISEASE}

Surgery remains the mainstay of therapy for patients with primary GIST with no evidence of metastasis, and should be the initial therapy if the tumor is technically resectable and the surgery carries acceptable morbidity risks. Intraoperatively, the tumor should be handled with care to avoid tumor rupture. If the pseudocapsule is torn, bleeding and tumor rupture may ensue. ${ }^{43}$ Intraoperative frozen section is usually not necessary; only highly experienced pathologists are likely to provide a diagnosis. The abdomen should be explored thoroughly with careful inspection of the liver and peritoneal surfaces, particularly the rectovaginal or rectovesical location in colorectal GISTs, to identify metastasis.

The goal is complete resection of all gross disease, which may necessitate the removal of adjacent organs. Segmental resection is adequate; lymphadenectomy is usually unnecessary, except in rare circumstances where an enlarged or otherwise suspicious lymph node is encountered. Incomplete resection should be performed only for the palliation of symptoms such as bleeding, pain, or mass effect.

In the case of rectal GISTs, transanal excision is recommended for non-high-risk GISTs, if technically feasible. ${ }^{44}$ Abdominoperineal resection should be considered only in patients with high risk or large, nonhigh-risk rectal GISTs. Studies demonstrate high incidence of relapse in the high-risk group even after complete resection and indicate a role for adjuvant treatment with KIT inhibitors. ${ }^{41,44,45}$ Changchien studied 42 patients with rectal GISTs and found that radical resection was superior to wide local excision in the prevention of local recurrence, but not that of distant metastases. ${ }^{14}$ Transvaginal excision of large low rectal tumors has been reported. ${ }^{46}$

DeMatteo published in 2000 an outcome study of 200 patients with GISTs treated at MSKCC between 1983 and 1997 and followed prospectively. ${ }^{47}$ Twenty-one of these patients had rectal tumors, and 11 had colon tumors. In patients with primary disease who underwent complete resection of gross disease $(n=80)$, the 5-year actuarial survival rate was $54 \%$. Survival was predicted by tumor size, but not microscopic margins of resection. This may be explained by the fact that many of these tumors are exophytic and protrude into the abdominal cavity. Therefore, the microscopic margin of resection of the organ from which they arise may not be as important as whether the tumor sheds cells directly into the peritoneal cavity.

Because the status of the microscopic margins does not appear to be critical for survival, vital structures should not be sacrificed if gross tumor clearance has already been attained. ${ }^{47}$ The management of a positive microscopic margin on the final pathology specimen is not clearly outlined and depends on whether the surgeon believes the finding accurately reflects the surgical procedure because resection specimens may retract and yield false-positive results. The NCCN guidelines report that there is no evidence of a need for re-excision, and recommend that the multidisciplinary team considers carefully the possible risks and benefits of re-excision, watchful waiting, or postoperative imatinib. A wider reexcision may be considered if technically feasible and without significant morbidity. ${ }^{16}$

Laparoscopy has been applied in the resection of GISTs, and small series of mainly gastric GISTs resected laparoscopically indicate this approach is safe with low recurrence rates. ${ }^{48}$ The data on laparoscopic resection of colorectal GISTs are very limited, but overall this approach could be feasible, especially for smaller tumors. ${ }^{49,50}$ The same principles of complete gross resection and careful handling of the tumor with avoidance of tumor rupture apply to laparoscopy. The specimen should be removed in a protective plastic bag to avoid port site recurrence.

In the case of distal or large rectal GISTs that require abdominoperineal resection, preoperative multidisciplinary review is critical, as neoadjuvant imatinib may produce downsizing of the tumor and allow for sphincter-sparing surgery.

\section{TREATMENT WITH TYROSINE KINASE INHIBITORS}

Gastrointestinal stromal tumors respond well to the newer targeted systemic therapies, imatinib mesylate and sunitinib malate. Prior to the tyrosine kinase inhibitors, there was no effective chemotherapy for GISTs, with studies yielding response rates between $0 \%$ and $5 \% .{ }^{51}$ 
The median survival for metastatic or unresectable GISTs prior to the introduction of imatinib was 12 months and has increased significantly in the imatinib era. ${ }^{52}$

Imatinib mesylate is a selective, potent, small molecule inhibitor of a family of structurally related tyrosine kinase signaling enzymes, including KIT, the leukemia-specific BCR-ABL chimera, and PDGFRA. Most GISTs have KIT mutations, and both mutant and nonmutant forms of KIT can be inhibited by imatinib. Based on the B2222 trial, the U.S. Food and Drug Administration (FDA) approved imatinib in 2002 for the treatment of patients with KIT-positive unresectable and/or metastatic GISTs. ${ }^{53,54}$

Sunitinib malate is a tyrosine kinase inhibitor that also acts on vascular endothelial growth factor receptors (VEGFR1-3), FMS-related tyrosine kinase 3, colonystimulating factor (CSF-) $1 \mathrm{R}$, and RET. It therefore possesses additional potential antiangiogenic activity. Preclinically, sunitinib inhibits some KIT mutant isoforms that are resistant to imatinib. In 2006 the FDA approved the use of sunitinib as second-line therapy in patients with advanced GISTs. ${ }^{55,56}$

\section{Adjuvant Treatment with TKIs}

Surgery alone is inadequate treatment for the majority of GISTs. Studies specifically indicate that most GISTs of the colon and rectum are high risk, with a significant likelihood of local and distant recurrence, and underscore the need for long-term follow-up and adjuvant therapy with TKIs. ${ }^{13,47,57}$

Imatinib was approved in 2008 by the FDA for postoperative treatment of patients after resection of KIT-positive GISTs. The American College of Surgeons Oncology Group (ACOSOG) Z9000 study, a single-arm, multicenter, phase II trial, concluded that postoperative imatinib prolonged recurrence-free survival (RFS) and overall survival (OS) compared with historical controls. ${ }^{58}$ Subsequently, the ACOSOG Z9001 study, a phase III, double-blind randomized trial of 713 patients, showed improvement in RFS of patients treated with imatinib compared with placebo. ${ }^{59}$ Updated results of this study were published in 2009, showing improved RFS (98\% vs $83 \%$ with placebo). ${ }^{60}$ There was no difference between the two groups in OS, which is not surprising, given the relatively short follow-up time and the crossover design of the study, which allowed patients assigned to the placebo arm to receive imatinib upon tumor recurrence. Imatinib was safe and well tolerated. The most frequently reported adverse reactions were diarrhea, fatigue, nausea, edema, decreased hemoglobin, rash, vomiting, and abdominal pain.

Treatment with imatinib after complete resection for primary GIST is currently recommended for at least 12 months for intermediate to high-risk patients. Higher-risk patients may require longer treatment. ${ }^{16}$ There are ongoing major trials in Europe investigating the efficacy of imatinib treatment for as long as 2-years (http://clinicaltrials/gov/ct2/show/NCT00101168) and 3-years postoperatively (http://clinicaltrials.gov/ct2/ show/NCT00116935).

Some patients develop resistance to imatinib, either almost immediately after initiation of treatment (primary resistance) or more than 6 months in their treatment (secondary resistance). Several series support a link between newly acquired (secondary) kinase mutations and late resistance to imatinib. ${ }^{61,62}$ Imatinib resistance can be managed by increasing the dose, but still with a relatively short time-to-disease progression. Alternatively, the patient can be switched to sunitinib. However, some imatinib-resistant disease will not respond to sunitinib. ${ }^{16}$

\section{Neoadjuvant Treatment with TKIs}

Two prospective, phase II trials have evaluated the use of imatinib in the neoadjuvant setting for all-site GISTs, with promising results for its efficacy and safety. ${ }^{63,64}$ Preoperative imatinib therapy has been shown in small studies and case reports to shrink large rectal GISTs, improving the chances of successful radical surgery and decreasing surgical morbidity (Fig. 3). ${ }^{65,66}$ Successful

A
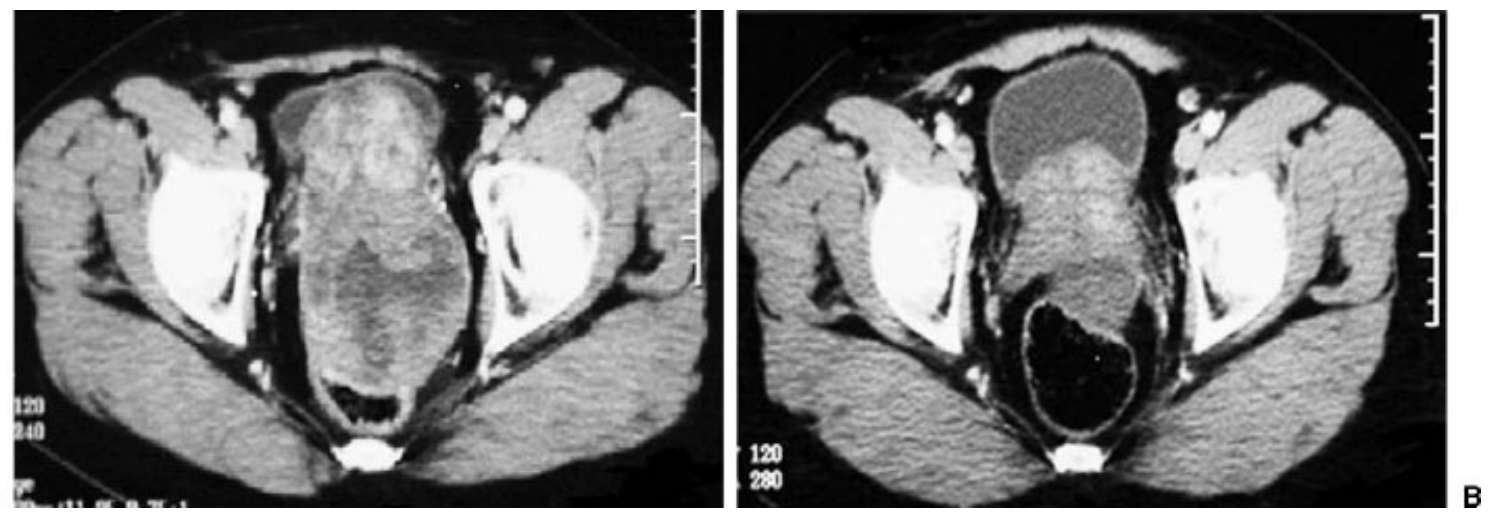

Figure 3 Tumor down-staging shown on a computed tomography scan. Rectal gastrointestinal stromal tumor $(A)$ pre- and $(B)$ post-imatinib. Adapted from Fiore et al. ${ }^{66}$ 
downsizing enough to allow local excision of large rectal GISTs has been reported. ${ }^{67-69}$ Complete pathologic response is possible. ${ }^{70,71}$ There is a case report of a rectal GIST extending to the anal canal treated with imatinib and radiotherapy, followed by sphincter-saving resection. $^{72}$

Because the optimal duration of preoperative therapy remains unknown, imatinib may be continued until maximal response is noted. Maximal response is defined as no further improvement between two successive CT scans, which can take as long as 6 to 12 months. ${ }^{73}$ However, it is not always necessary to wait for a maximal response to perform surgery. A multidisciplinary team should be following these patients and reevaluate the decision for surgery versus continuation of preoperative imatinib after every imaging series.

\section{TREATMENT OF RECURRENT OR METASTATIC DISEASE}

The median time to recurrence after resection of primary GISTs is $\sim 2$ years. ${ }^{74}$ Of note, a remarkably long course of disease is not uncommon, and recurrence, local and distant, 10 years after the primary tumor may occur. GISTs metastasize predominantly to the liver or the peritoneal surfaces. They rarely metastasize to lymph nodes. Rectal GISTs also metastasize to the lung and bone. $^{2}$

Imatinib is the mainstay of treatment of recurrent or metastatic disease. ${ }^{54}$ Cytoreductive surgery may be used in addition to imatinib in selected patients. Studies suggest that debulking procedures may prolong survival in patients with stable disease or limited progression on TKIs. ${ }^{75,76}$ There are case reports of recurrent rectal GISTs resected successfully after treatment with imatinib. ${ }^{77,78}$ Surgery also has a role in emergencies, such as bleeding, perforation, obstruction, or abscess. It should be considered in addition for impending emergencies, such as tumors with significant cystic degeneration and risk of perforation.

Imatinib can be given to patients until surgery and restarted when the patients resume oral intake postoperatively. Sunitinib is stopped 5 to 7 days before surgery and restarted 2 weeks after the surgery.

\section{CONCLUSIONS}

In summary, colorectal GISTs are rare tumors with overall higher risk behavior than gastric GISTs. Small tumors with low mitotic activity have a benign course and can be safely treated with transanal excision. Larger or more aggressive tumors require radical resection and adjuvant treatment with imatinib. Long-term surveillance is needed. Salvage therapy with TKIs and possible re-excision in selected patients may significantly prolong survival. A multidisciplinary team approach is essential to provide the best treatment results.

\section{REFERENCES}

1. Miettinen M, Lasota J. Gastrointestinal stromal tumors: review on morphology, molecular pathology, prognosis, and differential diagnosis. Arch Pathol Lab Med 2006;130(10): 1466-1478

2. Miettinen M, Furlong M, Sarlomo-Rikala M, Burke A, Sobin LH, Lasota J. Gastrointestinal stromal tumors, intramural leiomyomas, and leiomyosarcomas in the rectum and anus: a clinicopathologic, immunohistochemical, and molecular genetic study of 144 cases. Am J Surg Pathol 2001; 25(9):1121-1133

3. Miettinen M, Sarlomo-Rikala M, Sobin LH, Lasota J. Gastrointestinal stromal tumors and leiomyosarcomas in the colon: a clinicopathologic, immunohistochemical, and molecular genetic study of 44 cases. Am J Surg Pathol 2000;24(10): 1339-1352

4. Robinson TL, Sircar K, Hewlett BR, Chorneyko K, Riddell RH, Huizinga JD. Gastrointestinal stromal tumors may originate from a subset of CD34-positive interstitial cells of Cajal. Am J Pathol 2000;156(4):1157-1163

5. Du CY, Shi YQ, Zhou Y, Fu H, Zhao G. The analysis of status and clinical implication of KIT and PDGFRA mutations in gastrointestinal stromal tumor (GIST). J Surg Oncol 2008;98(3):175-178

6. Lasota J, Miettinen M. Clinical significance of oncogenic KIT and PDGFRA mutations in gastrointestinal stromal tumours. Histopathology 2008;53(3):245-266

7. Lasota J, Jasinski M, Sarlomo-Rikala M, Miettinen M. Mutations in exon 11 of c-Kit occur preferentially in malignant versus benign gastrointestinal stromal tumors and do not occur in leiomyomas or leiomyosarcomas. Am J Pathol 1999;154(1): 53-60

8. Andersson J, Bümming P, Meis-Kindblom JM, et al. Gastrointestinal stromal tumors with KIT exon 11 deletions are associated with poor prognosis. Gastroenterology 2006;130(6): 1573-1581

9. Rubin BP, Singer S, Tsao C, et al. KIT activation is a ubiquitous feature of gastrointestinal stromal tumors. Cancer Res 2001;61(22):8118-8121

10. Corless CL, McGreevey L, Haley A, Town A, Heinrich MC. KIT mutations are common in incidental gastrointestinal stromal tumors one centimeter or less in size. Am J Pathol 2002;160(5):1567-1572

11. Lasota J, Miettinen M. KIT and PDGFRA mutations in gastrointestinal stromal tumors (GISTs). Semin Diagn Pathol 2006;23(2):91-102

12. Hou YY, Grabellus F, Weber F, et al. Impact of KIT and PDGFRA gene mutations on prognosis of patients with gastrointestinal stromal tumors after complete primary tumor resection. J Gastrointest Surg 2009;13(9):15831592

13. Hassan I, You YN, Dozois EJ, et al. Clinical, pathologic, and immunohistochemical characteristics of gastrointestinal stromal tumors of the colon and rectum: implications for surgical management and adjuvant therapies. Dis Colon Rectum 2006;49(5):609-615

14. Changchien CR, Wu MC, Tasi WS, et al. Evaluation of prognosis for malignant rectal gastrointestinal stromal tumor 
by clinical parameters and immunohistochemical staining. Dis Colon Rectum 2004;47(11):1922-1929

15. Hirota S, Ohashi A, Nishida T, et al. Gain-of-function mutations of platelet-derived growth factor receptor alpha gene in gastrointestinal stromal tumors. Gastroenterology 2003;125(3):660-667

16. Demetri GD, von Mehren M, Antonescu CR, et al. NCCN task force report: update on the management of patients with gastrointestinal stromal tumors. J Natl Compr Canc Netw 2010;8(Suppl 2):S1-S41, quiz S42-S44

17. Levy AD, Remotti HE, Thompson WM, Sobin LH, Miettinen M. Anorectal gastrointestinal stromal tumors: CT and MR imaging features with clinical and pathologic correlation. AJR Am J Roentgenol 2003;180(6):1607-1612

18. Ji F, Wang ZW, Wang LJ, Ning JW, Xu GQ. Clinicopathological characteristics of gastrointestinal mesenchymal tumors and diagnostic value of endoscopic ultrasonography. J Gastroenterol Hepatol 2008;23(8 Pt 2):e318-e324

19. van den Berg JC, van Heesewijk JP, van Es HW. Malignant stromal tumour of the rectum: findings at endorectal ultrasound and MRI. Br J Radiol 2000;73(873):1010-1012

20. Ha CY, Shah R, Chen J, Azar RR, Edmundowicz SA, Early DS. Diagnosis and management of GI stromal tumors by EUS-FNA: a survey of opinions and practices of endosonographers. Gastrointest Endosc 2009;69(6):1039-1044, e1

21. Sepe PS, Brugge WR. A guide for the diagnosis and management of gastrointestinal stromal cell tumors. Nat Rev Gastroenterol Hepatol 2009;6(6):363-371

22. Akahoshi K, Sumida Y, Matsui N, et al. Preoperative diagnosis of gastrointestinal stromal tumor by endoscopic ultrasound-guided fine needle aspiration. World J Gastroenterol 2011;13(14):2077-2082

23. Elliott DD, Fanning CV, Caraway NP. The utility of fineneedle aspiration in the diagnosis of gastrointestinal stromal tumors: a cytomorphologic and immunohistochemical analysis with emphasis on malignant tumors. Cancer 2006;108(1): 49-55

24. Sarlomo-Rikala M, Kovatich AJ, Barusevicius A, Miettinen M. CD117: a sensitive marker for gastrointestinal stromal tumors that is more specific than CD34. Mod Pathol 1998;11(8):728-734

25. Miettinen M, Sobin LH, Sarlomo-Rikala M. Immunohistochemical spectrum of GISTs at different sites and their differential diagnosis with a reference to CD117 (KIT). Mod Pathol 2000;13(10):1134-1142

26. Miettinen M, Lasota J. Gastrointestinal stromal tumors (GISTs): definition, occurrence, pathology, differential diagnosis and molecular genetics. Pol J Pathol 2003;54(1):3-24

27. Katz SC, DeMatteo RP. Gastrointestinal stromal tumors and leiomyosarcomas. J Surg Oncol 2008;97(4):350-359

28. Yamaguchi U, Hasegawa T, Masuda T, et al. Differential diagnosis of gastrointestinal stromal tumor and other spindle cell tumors in the gastrointestinal tract based on immunohistochemical analysis. Virchows Arch 2004;445(2):142-150

29. Fletcher CD, Berman JJ, Corless C, et al. Diagnosis of gastrointestinal stromal tumors: a consensus approach. Hum Pathol 2002;33(5):459-465

30. Miettinen M, Sobin LH, Lasota J. Gastrointestinal stromal tumors of the stomach: a clinicopathologic, immunohistochemical, and molecular genetic study of 1765 cases with long-term follow-up. Am J Surg Pathol 2005;29(1):52-68

31. Miettinen M, Makhlouf H, Sobin LH, Lasota J. Gastrointestinal stromal tumors of the jejunum and ileum: a clinicopathologic, immunohistochemical, and molecular genetic study of 906 cases before imatinib with long-term follow-up. Am J Surg Pathol 2006;30(4):477-489

32. Miettinen M, Lasota J. Gastrointestinal stromal tumorsdefinition, clinical, histological, immunohistochemical, and molecular genetic features and differential diagnosis. Virchows Arch 2001;438(1):1-12

32a. Agaimy A. Gastrointestinal stromal tumors (GIST) from risk stratification systems to the new TNM proposal: more questions than answers? A review emphasizing the need for a standardized GIST reporting. Int J Clin Exp Pathol 2010; 3(5):461-471

33. Martín J, Poveda A, Llombart-Bosch A, et al; Spanish Group for Sarcoma Research. Deletions affecting codons 557-558 of the c-KIT gene indicate a poor prognosis in patients with completely resected gastrointestinal stromal tumors: a study by the Spanish Group for Sarcoma Research (GEIS). J Clin Oncol 2005;23(25):6190-6198

34. Miettinen M, Lasota J. Gastrointestinal stromal tumors: pathology and prognosis at different sites. Semin Diagn Pathol 2006;23(2):70-83

35. Dematteo RP, Gold JS, Saran L, et al. Tumor mitotic rate, size, and location independently predict recurrence after resection of primary gastrointestinal stromal tumor (GIST). Cancer 2008;112(3):608-615

36. Gold JS, Gönen M, Gutiérrez A, et al. Development and validation of a prognostic nomogram for recurrence-free survival after complete surgical resection of localised primary gastrointestinal stromal tumour: a retrospective analysis. Lancet Oncol 2009;10(11):1045-1052

37. Tsai MC, Lin JW, Lin SE, Chen HH, Lee CM, Hu TH. Prognostic analysis of rectal stromal tumors by reference of National Institutes of Health risk categories and immunohistochemical studies. Dis Colon Rectum 2008;51(10):15351543

38. Hu TH, Tai MH, Chuah SK, et al. Elevated p21 expression is associated with poor prognosis of rectal stromal tumors after resection. J Surg Oncol 2008;98(2):117-123

39. Hu TH, Lin JW, Chen HH, Liu LF, Chuah SK, Tai MH. The expression and prognostic role of hepatoma-derived growth factor in colorectal stromal tumors. Dis Colon Rectum 2009;52(2):319-326

40. Tai WC, Chuah SK, Lin JW, et al. Colorectal mesenchymal tumors - from smooth muscle tumors to stromal tumors. Oncol Rep 2008;20(5):1157-1164

41. Dong C, Jun-Hui C, Xiao-Jun Y, et al. Gastrointestinal stromal tumors of the rectum: clinical, pathologic, immunohistochemical characteristics and prognostic analysis. Scand J Gastroenterol 2007;42(10):1221-1229

42. Weber AG, Jovenin N, Lubrano D, et al. Outcome after surgical treatment of gastrointestinal stromal tumors. Gastroenterol Clin Biol 2007;31(6-7):579-584

43. Hohenberger P, Ronellenfitsch U, Oladeji O, et al. Pattern of recurrence in patients with ruptured primary gastrointestinal stromal tumour. Br J Surg 2010;97(12):1854-1859

44. Chen CW, Wu CC, Hsiao CW, et al. Surgical management and clinical outcome of gastrointestinal stromal tumor of the colon and rectum. Z Gastroenterol 2008; 46(8):760-765

45. Li JC, Ng SS, Lo AW, Lee JF, Yiu RY, Leung KL. Outcome of radical excision of anorectal gastrointestinal stromal tumors in Hong Kong Chinese patients. Indian J Gastroenterol 2007;26(1):33-35 
46. Hellan M, Maker VK. Transvaginal excision of a large rectal stromal tumor: an alternative. Am J Surg 2006;191(1):121123

47. DeMatteo RP, Lewis JJ, Leung D, Mudan SS, Woodruff JM, Brennan MF. Two hundred gastrointestinal stromal tumors: recurrence patterns and prognostic factors for survival. Ann Surg 2000;231(1):51-58

48. Nishimura J, Nakajima K, Omori T, et al. Surgical strategy for gastric gastrointestinal stromal tumors: laparoscopic vs. open resection. Surg Endosc 2007;21(6):875-878

49. Chang SC, Ke TW, Chiang HC, Wu C, Chen WT. Laparoscopic excision is an alternative method for rectal gastrointestinal stromal tumor. Surg Laparosc Endosc Percutan Tech 2010;20(4):284-287

50. Nakamura T, Ihara A, Mitomi H, et al. Gastrointestinal stromal tumor of the rectum resected by laparoscopic surgery: report of a case. Surg Today 2007;37(11):10041008

51. Edmonson JH, Marks RS, Buckner JC, Mahoney MR. Contrast of response to dacarbazine, mitomycin, doxorubicin, and cisplatin (DMAP) plus GM-CSF between patients with advanced malignant gastrointestinal stromal tumors and patients with other advanced leiomyosarcomas. Cancer Invest 2002;20(5-6):605-612

52. Artinyan A, Kim J, Soriano P, Chow W, Bhatia S, Ellenhorn JD. Metastatic gastrointestinal stromal tumors in the era of imatinib: improved survival and elimination of socioeconomic survival disparities. Cancer Epidemiol Biomarkers Prev 2008; 17(8):2194-2201

53. Demetri GD, von Mehren M, Blanke CD, et al. Efficacy and safety of imatinib mesylate in advanced gastrointestinal stromal tumors. N Engl J Med 2002;347(7):472-480

54. Dagher R, Cohen M, Williams G, et al. Approval summary: imatinib mesylate in the treatment of metastatic and/or unresectable malignant gastrointestinal stromal tumors. Clin Cancer Res 2002;8(10):3034-3038

55. Demetri GD, van Oosterom AT, Garrett CR, et al. Efficacy and safety of sunitinib in patients with advanced gastrointestinal stromal tumour after failure of imatinib: a randomised controlled trial. Lancet 2006;368(9544):13291338

56. Demetri GD, Huang X, Garrett CR, et al. Novel statistical analysis of long-term survival to account for crossover in a phase III trial of sunitinib (SU) vs. placebo (PL) in advanced GIST afterimatinib (IM) failure. [abstract]J Clin Oncol 2008;26(Suppl 1):A10524

57. Hassan I, You YN, Shyyan R, et al. Surgically managed gastrointestinal stromal tumors: a comparative and prognostic analysis. Ann Surg Oncol 2008;15(1):52-59

58. DeMatteo RP, Owzar K, Antonescu CR, et al. Efficacy of adjuvant imatinib mesylate following complete resection of localized, primary gastrointestinal stromal tumor (GIST) at high risk of recurrence: the U.S. Intergroup phase II trial ACOSOG Z9000 [abstract 8]. Abstract presented at: The 2008 ASCO Gastrointestinal Cancers Symposium; January 25-27, 2008; Orlando, FL.

59. DeMatteo R, Owzar K, Maki R, et al. Adjuvant imatinib mesylate increases recurrence free survival (RFS) in patients with completely resected localized primary gastrointestinal stromal tumor (GIST): North American Intergroup Phase III trial ACOSOG Z9001 [abstract 10079]. Abstract presented at: The 43rd ASCO Annual Meeting; June 1-5, 2007; Chicago, IL.
60. Dematteo RP, Ballman KV, Antonescu CR, et al; American College of Surgeons Oncology Group (ACOSOG) Intergroup Adjuvant GIST Study Team. Adjuvant imatinib mesylate after resection of localised, primary gastrointestinal stromal tumour: a randomised, doubleblind, placebo-controlled trial. Lancet 2009;373(9669): 1097-1104

61. Antonescu CR, Besmer P, Guo T, et al. Acquired resistance to imatinib in gastrointestinal stromal tumor occurs through secondary gene mutation. Clin Cancer Res 2005;11(11): 4182-4190

62. Heinrich MC, Corless CL, Blanke CD, et al. Molecular correlates of imatinib resistance in gastrointestinal stromal tumors. J Clin Oncol 2006;24(29):4764-4774

63. Eisenberg BL, Harris J, Blanke CD, et al. Phase II trial of neoadjuvant/adjuvant imatinib mesylate (IM) for advanced primary and metastatic/recurrent operable gastrointestinal stromal tumor (GIST): early results of RTOG 0132/ACRIN 6665. J Surg Oncol 2009;99(1):42-47

64. McAuliffe JC, Hunt KK, Lazar AJ, et al. A randomized, phase II study of preoperative plus postoperative imatinib in GIST: evidence of rapid radiographic response and temporal induction of tumor cell apoptosis. Ann Surg Oncol 2009; 16(4):910-919

65. Machlenkin S, Pinsk I, Tulchinsky H, et al. The effect of neoadjuvant imatinib therapy on rectal gastrointestinal stromal tumours outcome and survival. Colorectal Dis 2010doi:10.1111/j.1463-1318.2010.02442.x[Epub ahead of print]

66. Fiore M, Palassini E, Fumagalli E, et al. Preoperative imatinib mesylate for unresectable or locally advanced primary gastrointestinal stromal tumors (GIST). Eur J Surg Oncol 2009;35(7):739-745

67. Wang JP, Wang T, Huang MJ, Wang L, Kang L, Wu XJ. The role of neoadjuvant imatinib mesylate therapy in sphincter-preserving procedures for anorectal gastrointestinal stromal tumor. Am J Clin Oncol 2011;34(3): 314-316

68. Sekoguchi S, Okuyama Y, Enoki Y, et al. [A case of rectal GIST treated with imatinib mesylate neoadjuvant therapy to preserve the anus]. Nippon Shokakibyo Gakkai Zasshi 2009;106(12):1751-1757

69. Hou YY, Zhou Y, Lu SH, et al. Imatinib mesylate neoadjuvant treatment for rectal malignant gastrointestinal stromal tumor. World J Gastroenterol 2009;15(15):1910 1913

70. Mandalà M, Pezzica E, Tamborini E, et al. Neoadjuvant imatinib in a locally advanced gastrointestinal stromal tumour (GIST) of the rectum: a rare case of two GISTs within a family without a familial GIST syndrome. Eur J Gastroenterol Hepatol 2007;19(8):711-713

71. de Azevedo CR, Paiva TF Jr, Rossi BM, et al. Pathologic complete response with neoadjuvant imatinib for locally advanced pelvic GIST. Int J Clin Oncol 2011;16(3): 279-283

72. Ciresa M, D'Angelillo RM, Ramella S, et al. Molecularly targeted therapy and radiotherapy in the management of localized gastrointestinal stromal tumor (GIST) of the rectum: a case report. Tumori 2009;95(2):236-239

73. Bonvalot S, Eldweny H, Péchoux CL, et al. Impact of surgery on advanced gastrointestinal stromal tumors (GIST) in the imatinib era. Ann Surg Oncol 2006;13(12): 1596-1603 
74. Li J, Gong FJ, Wu WA, Shen L. Adjuvant therapy with imatinib in gastrointestinal stromal tumor (GIST) patients with intermediate or high risk: analysis from a single-center contrast study. [abstract].J Clin Oncol 2009;27(Suppl 1): A10556

75. Raut CP, Posner M, Desai J, et al. Surgical management of advanced gastrointestinal stromal tumors after treatment with targeted systemic therapy using kinase inhibitors. J Clin Oncol 2006;24(15):2325-2331

76. DeMatteo RP, Maki RG, Singer S, Gonen M, Brennan MF, Antonescu CR. Results of tyrosine kinase inhibitor therapy followed by surgical resection for metastatic gastrointestinal stromal tumor. Ann Surg 2007;245(3):347-352

77. Hamada M, Ozaki K, Horimi T, et al. Recurrent rectal GIST resected successfully after preoperative chemotherapy with imatinib mesylate. Int J Clin Oncol 2008;13(4): 355-360

78. Tsutsui M, Yoshino S, Sakamoto K, Oka M. [Long-term survival after surgery and adjuvant imatinib in a patient with rectal GIST, local recurrence, liver metastases and mediastinal pleural metastasis]. Gan To Kagaku Ryoho 2009; 36(12):2351-2353 